This retrospective observational study aims to examine survival to discharge from UK and Irish Paediatric Intensive Care Units (PICU) for children receiving exchange transfusion in the setting of pertussis.

Methods Retrospective data was requested from the Paediatric Intensive Care Audit network (PICAnet) with regards to completed exchange transfusions within UK and Irish Paediatric Intensive Care Units between 2007 and 2015. Reported instances of exchange transfusion in the setting of pertussis were then identified and analysed.

Results In total 25 exchange transfusions in the setting of pertussis were reported to PICAnet between 2007 and 2015. During this time, 167,462 PICU admissions were also reported. This equated to an average of 2.8 per year and an incidence of 1.5 per 10000 admissions to UK and Irish PICUs.

The average age of these children was 1.7 months (range 21 days to 83 days) with average length of PICU stay 12 days.

In total 14 children (56\%) survived to PICU discharge.

Conclusions Exchange transfusion in the setting of severe pertussis is a rare occurrence with incidence in UK and Ireland of 1.5 per 10,000 PICU admissions. The overall PICU survival rate for pertussis requiring exchange transfusion reported between 2007 and 2015 was 56\%.

Acknowledgement The authors would like to thank PICAnet for providing the data used in the study.

\section{G27(P) PROMOTING FAMILY-CENTRED CARE: ASSESSING PARENT \& HEALTHCARE PROFESSIONALS' VIEWS ON INTRODUCING PARENTAL PRESENCE ON PICU WARD ROUNDS}

${ }^{1} \mathrm{P}$ Mallett, ${ }^{2} \mathrm{~S}$ Willis, ${ }^{2} \mathrm{JP}$ Corrigan, ${ }^{3} \mathrm{H}$ Keenan, ${ }^{3} \mathrm{H}$ Tough, ${ }^{3} \mathrm{M}$ Terris, ${ }^{3}$ J Richardson. ${ }^{1}$ Clinical Fellow in Education and Simulation, Royal Belfast Hospital for Sick Children, Belfast, UK; ${ }^{2}$ Department of Clinical Psychology, Royal Belfast Hospital for Sick Children, Belfast, UK; ${ }^{3}$ Department of Paediatric Intensive Care, Royal Belfast Hospital for Sick Children, Belfast, UK

\subsection{6/archdischild-2018-rcpch.26}

Aims Paediatric Intensive Care Unit (PICU) is a challenging environment. Being a parent to a child who is critically unwell creates a variety of complex emotions. Often the unwell child is not able to express their needs, and thus healthcare professionals must recognise the invaluable role parents play in this situation. ${ }^{1}$ Communication between parents and staff is an essential part of the support offered during these difficult times and may reduce parent's emotional stress. $^{2}$

Currently, RBHSC PICU does not facilitate parents to be present during morning PICU ward rounds. There are several reasons cited for this, including potential excess length of ward rounds and possible confidentiality implications due to the unique and often sensitive patient circumstances in a critical care environment. This practice is consistent with several other large PICU Centres in the UK and Ireland.

We introduced the concept of parents being invited to be present during the daily morning ward round and proposed a multitude of benefits for patients, parents and staff.

Methods A questionnaire was designed assessing staff and parent attitudes on parental presence on ward rounds. Parents and legal guardians of patients admitted to PICU for two successive mornings were eligible for participation. Focused questions included exploring themes around communication, empowerment, understanding day plans, and whether respondents felt parents should be invited to remain present during ward rounds. In addition, during a two-week period, we monitored length of time of ward rounds.

Results The average length of time for morning ward round was $14 \mathrm{~min}$ per patient. 12 Parents responded to questionnaire. 92\% were strongly in favour of being invited to stay for ward rounds. 70 PICU staff members responded including 56 Nurses, 9 Doctors, and 5 Allied health professionals. 30\% of staff agreed that parents should be invited, 23\% were equivocal, and $47 \%$ did not agree.

Conclusions This survey highlighted the varied staff and parent views on parental presence on PICU ward rounds. We plan to introduce a pilot period of parents being invited to stay present during the ward round and will re-survey to assess impact. These measures are in bid to enhance parental empowerment, improve communication and promote familycentred care in PICU.

\section{REFERENCES}

1. Latour, et al. Parent satisfactions in the paediatric ICU. Paediatric Clin N Am 2008:55:779-790.

2. Kuo DZ, Houtrow AJ, Arango P, Kuhlthau KA, Simmons JM, Neff JM. Family-centred care: Current applications and future directions in paediatric health care Matern Child Health J 2012;2012(16):297-305.

\section{G28(P) HOW CAN WE IMPROVE INDUCTION TO THE PAEDIATRIC AND NEONATAL INTENSIVE CARE UNITS?}

M Emedo. Intensive Care Unit, Great Ormond Street Hospital, London, UK

10.1136/archdischild-2018-rcpch.27

Background Our regional Paediatric and Neonatal Intensive Care Units (PICU and NICU) care for 1700 critically unwell children a year. Medical staffing is provided by senior paediatric or anaesthetic trainees, and overseas fellows from diverse professional backgrounds, starting at several different points throughout the year, completing rotations of 3-12 months.

The current induction programme is one day of talks followed in most cases by a day of shadowing prior to starting clinical duties. Anecdotal feedback from both doctors and nursing staff has suggested that many doctors do not start work feeling fully equipped for such a high intensity role, and there remains a steep learning curve.

Methods An online survey was disseminated to doctors, assessing both their experiences of the induction they had received and their ideas for how the programme could be made more effective. A separate survey was sent to nurses for their thoughts on how the transition could be improved.

Results Of 19 doctors who participated, 26\% felt the current induction format covered everything they needed to know to do their job effectively. $47 \%$ felt they had a good idea of what their job would be when they started but only $32 \%$ felt they had understood how the units worked. $68 \%$ found the shadowing period useful. 45 nurses contributed and only $13 \%$ felt new doctors started work with all the information they needed to do their jobs. Both staff groups identified key areas of difficulty, made suggestions for improvement and provided 'top tips' for new starters, based on information they felt would be important to know at the beginning of the rotation. Conclusion Both professional groups felt the induction programme needed improvement. It was highlighted that access to more written information would be beneficial prior to starting work. In response, an induction website has been 